\title{
Correction to: Effect of Sand Content on the Liquefaction Potential and Post-Earthquake Behaviour of Coode Island Silt
}

\author{
Hassan Jamali • Ali Tolooiyan
}

Published online: 30 October 2020

(C) Springer Nature Switzerland AG 2020

\section{Correction to: Geotech Geol Eng} https://doi.org/10.1007/s10706-020-

01512-1

In the original publication of the article, the table header values in Table 1 were published incorrectly. The corrected Table 1 is provided below:

The original article can be found online at https:// doi.org/10.1007/s10706-020-01512-1.

H. Jamali

Young Researchers and Elite Club, Sabzevar Branch,

Islamic Azad University, Sabzevar, Iran

\section{A. Tolooiyan $(\square)$}

School of Engineering, University of Tasmania,

Sandy Bay, TAS 7001, Australia

e-mail: ali.tolooiyan@utas.edu.au 
Table 1 Properties of cyclic triaxial tests

\begin{tabular}{lllll}
\hline Name of specimen & $\begin{array}{l}\text { Effective confining } \\
\text { pressure }(\mathrm{kPa}), p_{0}{ }^{\prime}\end{array}$ & $\begin{array}{l}\text { Cyclic stress } \\
\text { ratio, CSR }\end{array}$ & $\begin{array}{l}\text { Loading frequency } \\
(\mathrm{Hz})\end{array}$ & No. of cycles, N \\
\hline $\mathrm{SC}_{0}$ & $100,150,200$ & 0.3 & 1 & 100 \\
$\mathrm{SC}_{30}$ & & & \\
$\mathrm{SC}_{60}$ & & & \\
\hline
\end{tabular}

Publisher's Note Springer Nature remains neutral with regard to jurisdictional claims in published maps and institutional affiliations. 